\title{
THE EFFECT OF DIPHENHYDRAMINE ON THE HUMAN AND RABBIT ELECTROENCEPHALOGRAMS
}

\author{
KTYOSHI TANAKA \\ Department of Phirmacology, T'ottori University Sckool of Medicine, Yonago
}

Received for publication October 8, 1951

It is well known that some of the antihistaminic drug such as diphenhydramine has marked hypnotic action. The mechanism of this action is, however, remaired obscure for it acts in experimental animal not as a central depressant but rather as a central stimulant. An attempt was made, therefore, to compare the effect of this drug upon the electroencephalogram (EEG) of man with that of rabbit.

Method: Unipolar electroencephalography was used. Brain potential was lead from the skin of forehead, both in man and in rabbit. Diphenhydramino hydrochloride (benadrin) was applied to man intravenously or orally and to rabbit intravenously or intraventricularly.

\section{RESUI:'}

\section{1) Human electroencephalogram}

One subject received $0.3 \mathrm{mg} / \mathrm{kg}$ of diphenhydramine intravenously (Fig. 1). He became drowsy within a few minutes, then complaired of faintirg sense, fatigue, dullness and chillness. Pulse rate diminished rapidly from 70 to below 60 . After

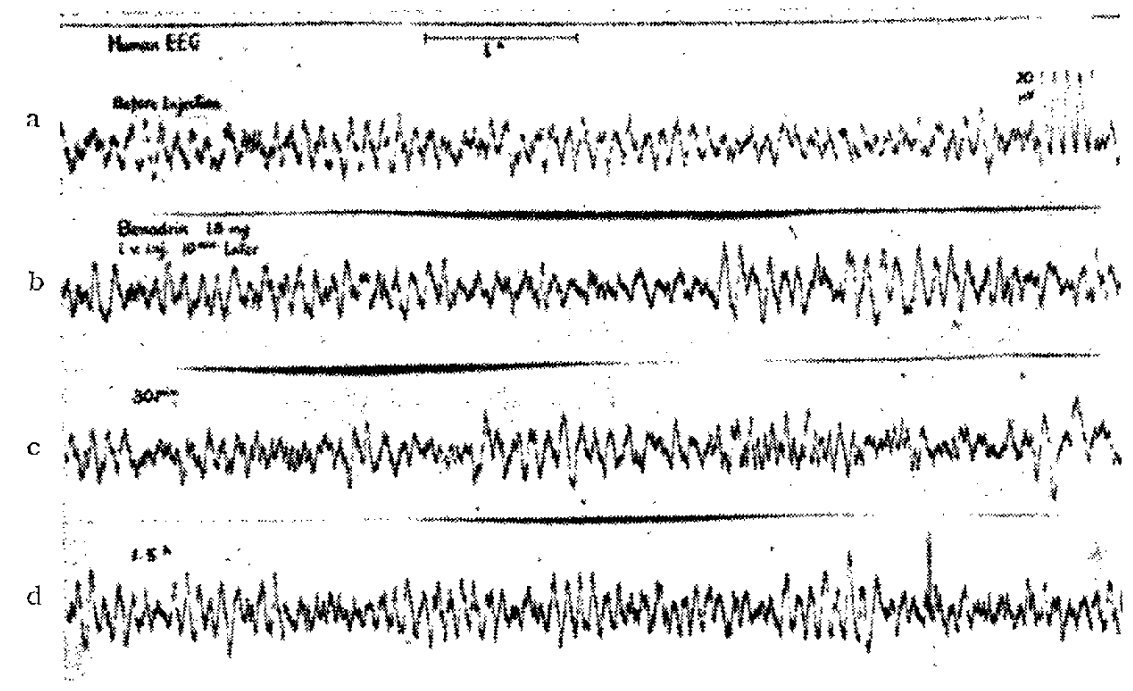

FIG. 1. EEG changes after diphenhydramine
a) Before drug administration,
b) $10 \mathrm{~min}$. after intravenous injection of benadrin,
c) 30 min. later,
d) 1.5 hours later. 
ten minutes from injection, his EEG, which ofherwise presented a continuation of regular alpha activity, showed some reduction in regularity of alpha rhythm, slight prolongation of alpha period and appearance of a flattening phase in the record. Thirty minutes later, when the drug action reached its maximum, alpha activity lost its regularity moderately, larger fast activity of 14-20 cycles and irregular slow activity being interposed. These findings are similar to EEG changes at onset of sleep, as Davis and Lomis (1) described. In spite of intense drowsiness, the subject did not fall asleep but was kept in the state of nothing to think or to do. One and a half hour later EEG regained its regularity, when the subject had almost recovered from the drug action.

Another subject, whose brain wave pattern consisted of nainly beta rhythm and of very poor alpha, received $0.5 \mathrm{mg} / \mathrm{kg}$ of diphenhydramire intravenously (Fig. 2). Tho physical reactions were quite analogous to the former subject, but the EEG charge was not the same. Alpha activity, which was hardly recognized befors diug application, appeared occasionally after medication, so that the whole pattern incroased in amplitude and the fluttoring ot the rocord was revor roticed. At the peak of drug action, slow waves also appeared but fast activity remained unchanged.

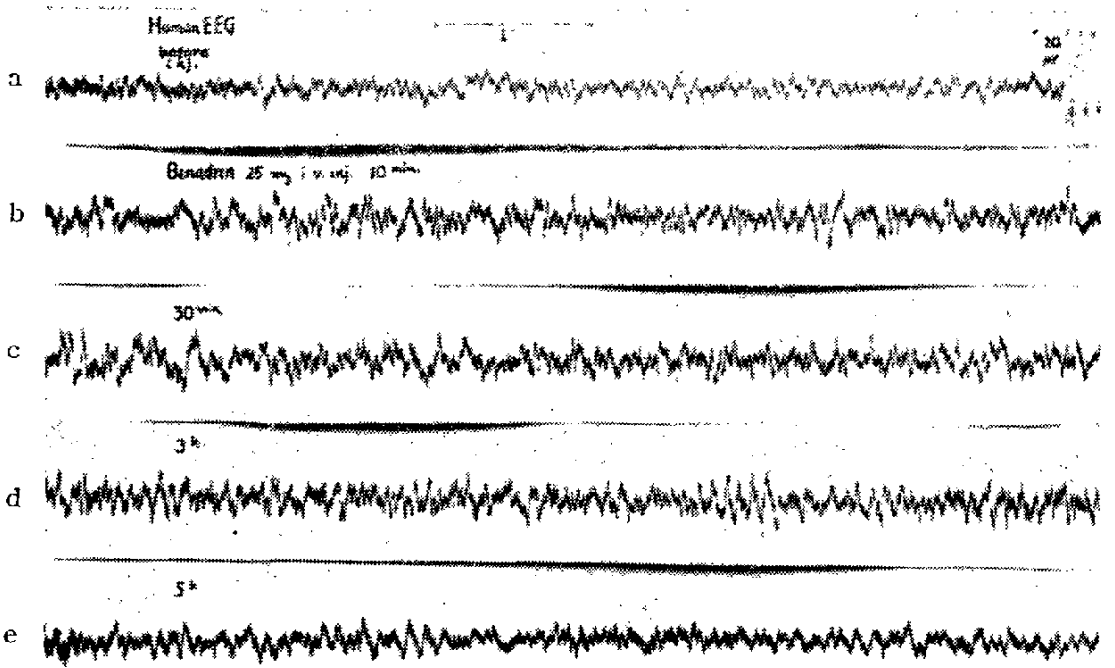

FIG. 2. EEG changes of the subject who has poor alpha rhythm

a) Before drug administration,

b) $10 \mathrm{~min}$. after intravenous injection of banadrin,

c) 39 min. later,

d) 3 hours later,

e) 5 hours later.

When the drug was applied orally to each of these subjects, the action was weaker and more prolonged and the EEG findings altered more indefinitely and indistinctly than in the case of intravenous application, although the tendency 
described above was still recognizad.

\section{2) Rabbit's electroencephalogram}

When diphenhydramine was injected intravenously to rabbit, the animal presented only excitement in behavior as Wyngaarden and Seevers (2) and other in. vestigators had reported. In my experiment, its EEG also showed usual change of central stimulation, i.e. predominance of fast activity; but no sign of central depression such as appearance of slow activity or flattening in the record was observed in any dose.

In the case of an administration of the drug into the side ventricle of rabbit's brain, the animal expressed marked drowsiness and occasionally fell asleep. On EEG it could be found that large high voltage slow waves, which superimposed smaller fast activity and interposed at times larger fast activity of $14-20$ cycles, dominated over the whole pattern (Fig. 3). These changes resemble partly the narcotic state by barbiturate, reported by Drohocki (3), Klaue (4) and others.

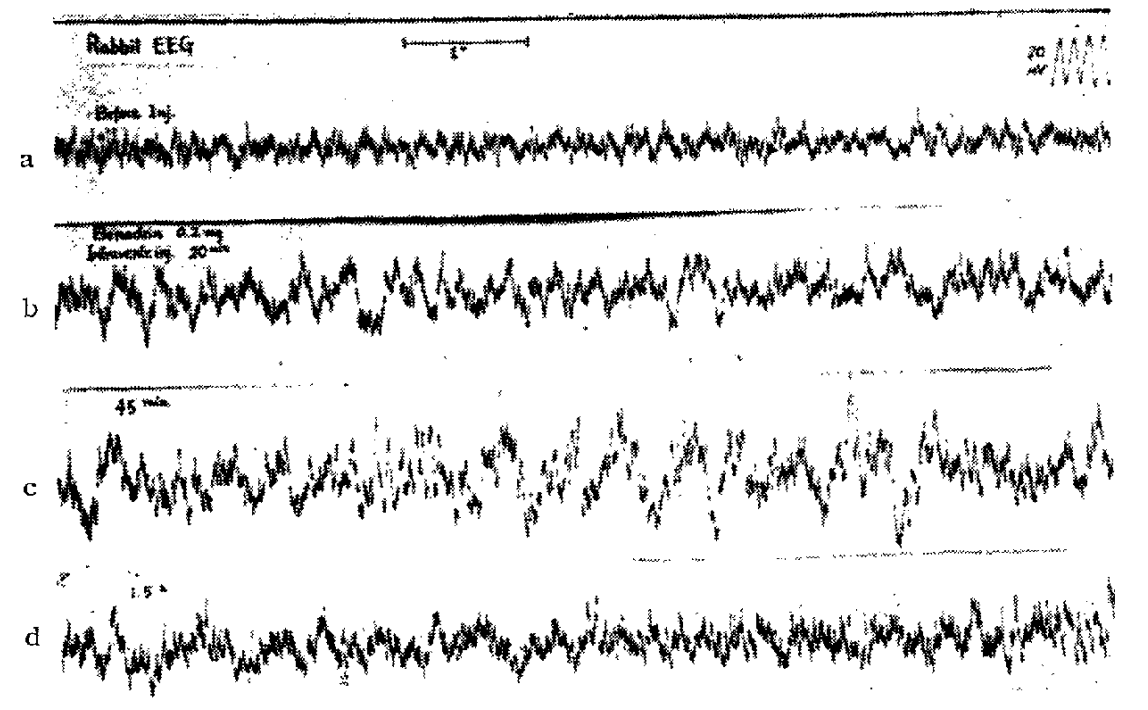

FIG. 3. Rabbit's EEG changes by administration of diphenhydramine intraventricularly

a) Before injection,

b) $20 \mathrm{~min}$. after injection into the side ventricle of brain,

c) 45 min. later,

d) 1.5 hours later.

\section{SUMMARY}

1. Electroencephalographic changes after the intravenous administration of diphenhydramine in man are different individually, according to the type of the characteristic encephalographic pattern of the subject. In general, however, they are similar to those at the state of onset of sleep.

2. In rabbit, intravenously injected diphenhydramine acts exclusively as a 
central stimulant. This is also proved by findings in electroencephalogram.

3. In rabbit, intraventricula-ly administered diphenhydramine acts as a central depressant and gives rise to a marked change in electroencephalogram, in which high voltage slow activity dominates, as it was in the case of barbiturate narcosis.

\section{REFERENCES}

1) Davis, H., Davis, P. A., LoOmis, A. L., HaRvey, E. N. AND HobaR'T, G.: J. Neurophysiol. 1, 24 (1988).

2) WYngaArden, J. B. ANd Seevers, M. H.: J. A. M. A. 145, 277 (1951).

3) DROHockI, Z. AND DRoHockA, J.: Arch. internat. pharmacodyn. 62, 265 (1939).

4) KLAUE, R.: J. Psychol. w. Newol. 47, 510 (1936).

This report is dedicated to Prof. T. Fukuda in Kyushu University to congratulate his 60 th birthday. 